\title{
Activities Scale for Kids
}

National Cancer Institute

\section{Source}

National Cancer Institute. Activities Scale for Kids. NCI Thesaurus. Code C78653.

A generic self-report tool developed to measure, describe, and evaluate changes in the level of daily life activities and performance in children aged 5-15 years. (Copyright Dr. Nancy L. Young) 